\title{
GEOQUÍMICA E ASPECTOS PETROGENÉTICOS DO GRANITO XINGUARA, TERRENO GRANITO-GREENSTONE ARQUEANO DE RIO MARIA - CRÁTON AMAZÔNICO
}

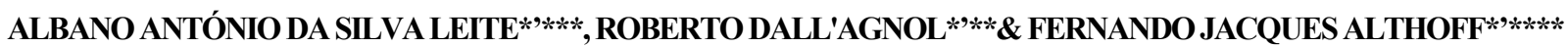

\begin{abstract}
GEOCHEMISTRY AND PETROGENETIC ASPECTS OF THE ARCHEAN XINGUARA GRANITE, RIO MARIA GRANITE-GREENSTONE TERRAIN - AMZONIAN CRATON The Xinguara Granite (XingG), an Archean granitic pluton situated in the northern part of the Rio Maria Granite-Greenstone Terrain, southeast of Para state, is intrusive in TTG granitoids and gneisses and in the Rio Maria Granodiorite. The XingG exhibits a remarkable compositional homogeneity, being composed essentially by metaluminous to slightly peraluminous leucogranite with high $\mathrm{SiCh}$ and alkali contents, high $\mathrm{K}_{2} \mathrm{O} / \mathrm{Na}_{2} \mathrm{O}$ ratios, low $\mathrm{MgO}$ and moderate CaO contents. Subordinate, it also occurs pegmatoid granites and leucosyenogranites. The leucomonzogranite fácies was subdivided on basis of the geochemical data in the LMG1 and LMG2 types, whole silica contents are similar. However, the LMG2 type has lower $\mathrm{Al}_{2} \mathrm{O}_{3} \mathrm{Cb}, \mathrm{MgO}, \mathrm{CaO}$ and Na $2 \mathrm{O}$ and higher $\mathrm{K}_{2} \mathrm{O}$, $\mathrm{Rb}, \mathrm{Zr}$ and Y contents compared to the LMG1 type. In geochemical diagrams the LMG1 and LMG2 types define contrasting evolutive trends, indicating that they crystallized from two different liquids. The behavior of lithophile elements suggests that a moderate fractionation of potassic feldspar, plagioclase and biotite controlled the small degree of differentiation of Xinguara pluton magmas. The fractionation of feldspar is confirmed by the deep Eu negative anomalies (Eu/Eu* ranging from 0.28 to 0.38 in the LMG1 type). The LMG1 type shows, in general, an acentuated depletion in the heavy rare earth elements $\left(\mathrm{La}_{\mathrm{n}} / \mathrm{Yb}_{\mathrm{n}}\right.$, ranging from 149.07 to 16.63), which is probably due to garnet and/or amphibole retention in the melt residue. The large extent of fractionation of the HREE, the depletion in $\mathrm{Y}$, Ti and Nb parallel to the enrichment in $\mathrm{P}$ e $\mathrm{Sr}$ in comparison to the average composition of the upper continental crust, as well as the high values of the $\mathrm{Rb} / \mathrm{Y}$ and $\mathrm{Al}_{2} \mathrm{O}_{3} / \mathrm{TiO}_{2}$ ratios, indicate a similarity between the Xinguara leucogranites and Archean calc-alkaline leucogranite of type 2 . The two types of Xinguara leucogranites were probably derived by different degrees of partial melting from a same crustal protolith, which is possibly similar to the TTG granitoids and gneisses or, alternatively, to the Rio Maria Granodiorite.
\end{abstract}

Keywords: Leucogranites, Calc-alkaline, Archean, Geochemistry, Petrogenesis, Amazoniam Craton.

RESUMO O Granito Xinguara, um corpo granítico Arqueano situado na porção norte do Terreno Granito-Greenstone de Rio Maria, sudeste do estado do Pará, é intrusivo em granitóides e gnaisses TTG e no Granodiorito Rio Maria. O Granito Xinguara exibe uma marcante homogeneidade composicional, sendo formado essencialmente por leucomonzogranitos metaluminosos a ligeiramente peraluminosos com altos teores de $\mathrm{SiO}_{2}$ e álcalis, elevadas razões $\mathrm{K}_{2} \mathrm{O} / \mathrm{Na}_{2} \mathrm{O}$, baixos teores médios de $\mathrm{MgO}$ e moderados de $\mathrm{CaO}$, havendo, ainda, granitos pegmatóides e leuco-sienogranitos subordinados. A fácies leucomonzogranito foi subdividida com base nos dados geoquímicos nos tipos LMG1 e LMG2, cujos teores de $\mathrm{SiOa}$ se superpõem. Entretanto, os LMG2 são empobrecidos em $\mathrm{Al}_{2} \mathrm{O}_{3} \mathrm{~s}, \mathrm{MgO}, \mathrm{CaO}$ e Na $\mathrm{O}_{2}$ e enriquecidos em $\mathrm{K}_{2} \mathrm{O}$, Rb, $\mathrm{Zr}$ e $\mathrm{Y}$, quando comparados aos LMG1. Em diagramas geoquímicos os LMG1 e LMG2 definem trends evolutivos contrastantes, indicarão que cristalizaram a partir de líquidos distintos. O comportamento dos elementos litófilos sugere que o fracionamento de feldspato potássico, plagioclásio e biotita controlou a evolução por cristalização fracionada dos magmas do pluton Xinguara. O fracionamento de feldspatos é indicado também pelas expressivas anomalias negativas de $\mathrm{Eu}\left(\mathrm{Eu} / \mathrm{Eu}^{*}\right.$, variando de 0,28 a 0,38 nos LMG1). Os LMG1 mostram, em geral, acentuado empobrecimento em terras raras pesados $\left(\mathrm{La}_{\mathrm{n}} / \mathrm{Yb}_{\mathrm{n}}\right.$, variando de 149,07 a 16,63) causado, provavelmente, pela retenção de granada e/ou anfibólios no resíduo de fusão. $\mathrm{O}$ acentuado fracionamento de terras raras pesados, o empobrecimento em Y, Ti e Nb, paralelamente ao enriquecimento em $\mathrm{P}$ e Sr, comparativamente à composição média da crosta continental superior, bem como os altos valores das razões $\mathrm{Rb} / \mathrm{Y}$ e $\mathrm{Ah}_{2} \mathrm{O}_{3} / \mathrm{TiO}_{2}$, apontam para uma similaridade dos leucogranitos Xinguara com os leucogranitos cálcico-alcalinos arqueanos do tipo 2. Os dois tipos de leucogranitos Xinguara provavelmente foram derivados a partir de diferentes graus de fusão parcial de uma mesma fonte crustal, possivelmente similar aos granitóides e gnaisses TTG ou afim ao Granodiorito Rio Maria.

Palavras-chaves: leucogranitos, cálcico-alcalinos, Arqueano, geoquímica, petrogênese, Craton Amazônico.

INTRODUÇÃO Os terrenos arqueanos de vários locais do mundo são constituídos fundamentalmente por associações granitóides dominadas por tonalitos, trondhjemitos e granodioritos que formam as clássicas associações TTG e por greenstone belts (Kröner 1991, Condie 1993, Martin 1994). Entretanto, maciços graníticos stricto sensu, embora geralmente menos discutidos, também possuem uma distribuição areal importante nesses terrenos (Cassidy et al. 1991, Sylvester 1994, Davis et al. 1994). Tais granitos formam plútons de dimensões variáveis, comumente intrusivos nas associações TTG. Condie (1993) estima que este magmatismo potássico constitui no mínimo cerca de $20 \%$ das rochas expostas nos crátons arqueanos, superando as rochas toleiíticas $( \pm 10 \%)$ e sendo subordinado apenas em relação às suítes TTG $(35 \mathrm{a} 50 \%)$.

No Terreno Granilo-Greenstone de Rio Maria (TGGRM) foram identificados os granitos Xinguara (Leite 1995) e Mata Surrão (Duarte 1992), bem como pequenos corpos leucograníticos na região de Identidade (Souza 1994), como representantes deste magmatismo granítico potássico de idade arqueana, o qual é inteiramente distinto da associação TTG. Posteriormente, Althoff (1996) mapeou na região de Marajoara diversos outros corpos de leucogranitos arqueanos, denominados de Granito Guarantã. Nos mapeamentos geológicos executados pela CPRM (Araújo \& Maia 1991), ficou igualmente comprovado que esses corpos graníticos possuem uma ampla distribuição no TGGRM. Além disso, na região da Serra dos Carajás e adjacências foi identificada uma outra sequência de leucogranitos arqueanos, definida como Suíte Plaque (Araújo et al. 1994), com idade de 2,73 Ga (Avelar 1996).
A importância do magmatismo potássico na evolução dos terrenos arqueanos da Amazónia Oriental acha-se, portanto, confirmada, reproduzindo-se um quadro similar ao verificado em outros continentes. Apesar disso, carece-se de estudos petrográficos e geoquímicos mais detalhados sobre corpos representativos desse magmatismo. Em razão do exposto, foram desenvolvidos esforços no sentido de caracterizar os granitos Mata Surrão (Duarte 1992), Xinguara (Leite 1995) e Guarantã (Althoff 1996)

O presente trabalho tem como objetivo principal discutir a geoquímica e os aspectos petrogenéticos do Granito Xinguara e contribuir para uma melhor compreensão da natureza desse granito, tendo em vista a sua importância na evolução geológica do TGGRM.

CONTEXTO GEOLÓGICO REGIONAL

O TGGRM é for

mado por rochas granitóides e unidades metavulcano-sedimentares tipo greenstone belt, parcialmente recobertas pelas sequências sedimentares anquimetamórficas arqueanas(?) do Grupo Rio Fresco e cortadas por granitos anorogênicos proterozóicos (Huhn et al. 1988, Araújo et al. 1994, Dall'Agnol et al. 1997).

Geoquimicamente, os granitóides arqueanos do TGGRM foram divididos em três grandes associações (Dall'Agnol et al 1997): (i) granitóides da série trondhjemítica, representados pelo Tonalito Arco Verde (Althoff 1996), Trondhjemito Mogno (Huhn et al 1988), Granitóides e gnaisses TTG de Xinguara (Leite 1995); (ii) Granodiorito Rio Maria e rochas afins (Medeiros \& Dall'Agnol 1988, Souza 1994), pertencentes à série de granitóides cálcio-alcalinos de alto magnésio e; (iii) leucogranitóides de composição monzogranítica e afinidade

* Grupo de Pesquisa Petrologia de Granitóides - GPPG

** Departamento de Geoquímica e Petrologia - CG/UFPa

*** Curso de Pós-Graduação em Geologia e Geoquímica -CPGG-CG-UFPa

****Universidade do Vale do Rio dos Sinos - UNISINOS/RS

Endereço para correspondência: Universidade Federal do Pará - Centro de Geociências, C.P. 1611, CEP. 66075-900 - Guamá - Belém - Pará. Tel: 091211

1477, Fax: 091211 1609, E-mail: albano@ufpa.br 
cálcio-alcalina, representados pelos grani tos Xinguara (Leite 1995, Leite \& Dall'Agnol 1997), Mata Surrão (Duarte 1992), Guarantã (Althoff 1996) e os leucogranitóides de Identidade (Souza 1994).

O Tonalito Arco Verde tem idade U-Pb em zircão de 2,96 Ga (Macambira \& Lafon 1995) e corresponde, juntamente com osgreenstone belts (2,90 Ga, Macambira \& Lafon 1995, e 2,97 Ga, Pimentel \& Machado 1994), às rochas mais antigas do TGGRM. Posteriormente, em torno de $2,87 \mathrm{Ga}$, a região foi cortada por diversos outros granitóides (Granodiorito Rio Maria, Trondhjemito Mogno, Tonalito Parazônia e Granito Mata Surrão) (Pimentel \& Machado 1994, Macambira \& Lafon 1995). A idade do Granito Xinguara não se encontra, ainda, bem definida, ao passo que um dos corpos que compõem o Granito Guarantã foi datado em 2,87 Ga (Althoff et al 1998).

\section{ASPECTOS GEOLÓGICOS E PETROGRÁFICOS DO GRA-}

NITO XINGUARA A área-tipo do Granito Xinguara está localizada nas cercanias de cidade homónima, na porção nordeste do Terreno Granito-Greenstone de Rio Maria (Fig. 1). Trata-se de um dos melhores exemplos do magmatismo granítico potássico de idade arqueana presente neste terreno.

O Granito Xinguara é um maciço granítico de forma amendoada, medindo cerca de $40 \mathrm{~km}$ no eixo maior e até $12 \mathrm{~km}$ no eixo menor. O eixo maior orienta-se subconcordantemente ao trend geral WNW-ESE da foliação das encaixantes (Fig. 1). Na porção sul o corpo granítico seciona os granitóides tonalito-trondhjemito-granodioritos e o Granodiorito Rio Maria; no norte está associado a trondhjemitos-granodioritos, com os quais intercala-se formando estruturas bandadas, interpretadas como de origem ígnea (Leite 1995, Leite \& Dall'Agnol 1997). Os trondhjemitos que ocorrem na parte norte da área são fortemente bandados e, inicialmente, foram correlacionados com os tonalitotrondhjemitos presentes a sul do corpo granítico. Atualmente está sendo avaliada a hipótese de existir mais de uma associação de tonalitotrondhjemitos na região, sendo possível que as rochas trondhjemíticas situadas a norte do corpo sejam mais jovens e estratigraficamente distintas daquelas mapeadas a sul.

A foliação no Granito Xinguara é pouco marcante, sendo mais evidente e penetrativa nas bordas, ao passo que no centro do corpo acha-se ausente ou mal definida. $\mathrm{O}$ granito encontra-se afetado por expressivas zonas de cisalhamento dúctil (Leite \& Dall'Agnol 1997). A deformação é heterogénea e não penetrativa em escalas meso e macroscópica. Os dados estruturais sugerem que a colocação do granito foi provavelmente condicionada pelas zonas de cisalhamento, tendo ocorrido durante o desenvolvimento das mesmas.
Petrografícamente o maciço é bastante homogéneo, sendo formado por leucogranitos subsolvus. Uma descricão petrográfica detalhada e composições modais de amostras das várias fácies constam em Leite \& Dali'Ảgnol (1997). As proporções de quartzo, plagioclásio e álcalifeldspato são equivalentes. A principal fase máfica é a biotita e, entre os acessórios, encontram-se magnetita, titanita, apatita, allanita, epídoto magmático(?) e zircão. Os constituintes secundários são epídoto, sericita-moscovita e, por vezes, carbonatos, clorita e hidróxidos de ferro. O Granito Xinguara é formado por três fácies petrográficas, predominando amplamente leucomonzogranitos, cortados por fases mais tardias representadas por sienogranitos e granitos pegmatóides. Apesar de terem sido afetadas por graus variados de deformação, as diversas fácies exibem texturas magmáticas facilmente reconhecidas. A deformação materializa-se através da intensa recristalização de cristais de feldspatos e quartzo, processada quando o corpo já se comportava como um sólido.

GEOQUIMICA Foram analisadas 20 amostras do corpo granítico (Tab. 1) para elementos maiores e menores $\left(\mathrm{SiO}_{2}, \mathrm{Al}_{2} \mathrm{O}_{3}, \mathrm{Fe}_{2} \mathrm{O}_{3}, \mathrm{CaO}\right.$, $\mathrm{MgO}, \mathrm{K}_{2} \mathrm{O}, \mathrm{Na}_{2} \mathrm{O}, \mathrm{TiO}_{2}, \mathrm{MnO}$ e $\mathrm{P}_{2} \mathrm{O}_{2}$ ) nos laboratórios da ALBRAS; o $\mathrm{FeO}$ e perda ao fogo foram obtidos no Laboratório de Análises Químicas e $\mathrm{Rb}, \mathrm{Sr}, \mathrm{Zr}, \mathrm{Nb}$ e Y no Laboratório de Fluorescência de Raios-X do Centro de Geociências da UFPA. Ba, Th, Ga e os elementos terras raras foram dosados no Laboratório GEOLAB da GEOSOL.

Aspectos Gerais Os teores de $\mathrm{SiO}_{2}$ das amostras analisadas variam de 71,70 a $75,30 \%$, refletindo a notável homogeneidade do corpo. Em vários diagramas geoquímicos é evidente a separação entre as diversas fácies do Granito Xinguara, bem como a discriminação de dois grupos de leucomonzogranitos: leucomonzogranitos do tipo 1 (LMG1), com teores normais de $\mathrm{K}_{2} \mathrm{O}\left(3,0 \leq \mathrm{K}_{2} \mathrm{O} \leq 5,24 \%\right.$; média de $4,77 \%$ ) e leucomonzogranitos do tipo 2 (LMG2), muito ricos em $\mathrm{K}_{2} \mathrm{O}$ $\left(\mathrm{K}_{2} \mathrm{O}>6 \%\right.$; média de 6,5\%) (Tab. 1; Fig. 2). Os LMG2 situam-se em um domínio bem definido na porção central do corpo, enquanto os LMG1 são dominantes e ocupam as demais porções do maciço (Fig. 1).

Os conteúdos de $\mathrm{SiO} 2$ dos dois tipos de leucomonzogranitos se superpõem, mas suas composições são distintas em vários aspectos. $\mathrm{Em}$ amostras com teores similares de $\mathrm{SiO}_{2}$ os LMG2 são comparativamente empobrecidos em $\mathrm{Al}_{2} \mathrm{O}_{3}, \mathrm{MgO}, \mathrm{CaO}$ e $\mathrm{Na}_{2} \mathrm{O}$ e enriquecidos em $\mathrm{K}_{2} \mathrm{O}, \mathrm{Rb}, \mathrm{Zr}$ e Y em relação aos LMG1. Nesses, $\mathrm{SiO}_{2}$ varia dentro de um intervalo mais amplo do que nos LMG2. Nos dois grupos, os teores de $\mathrm{Na}_{2} \mathrm{O}$ e $\mathrm{K}_{2} \mathrm{O}$ mantêm-se constantes ou pouco variam com o aumento de $\mathrm{SiO}_{2}$ (Fig. 2). As razões $\mathrm{K}_{2} \mathrm{O} / \mathrm{Na}_{2} \mathrm{O}$ médias são de 1,26 para os LMG1 e de 2,06 para os LMG2.

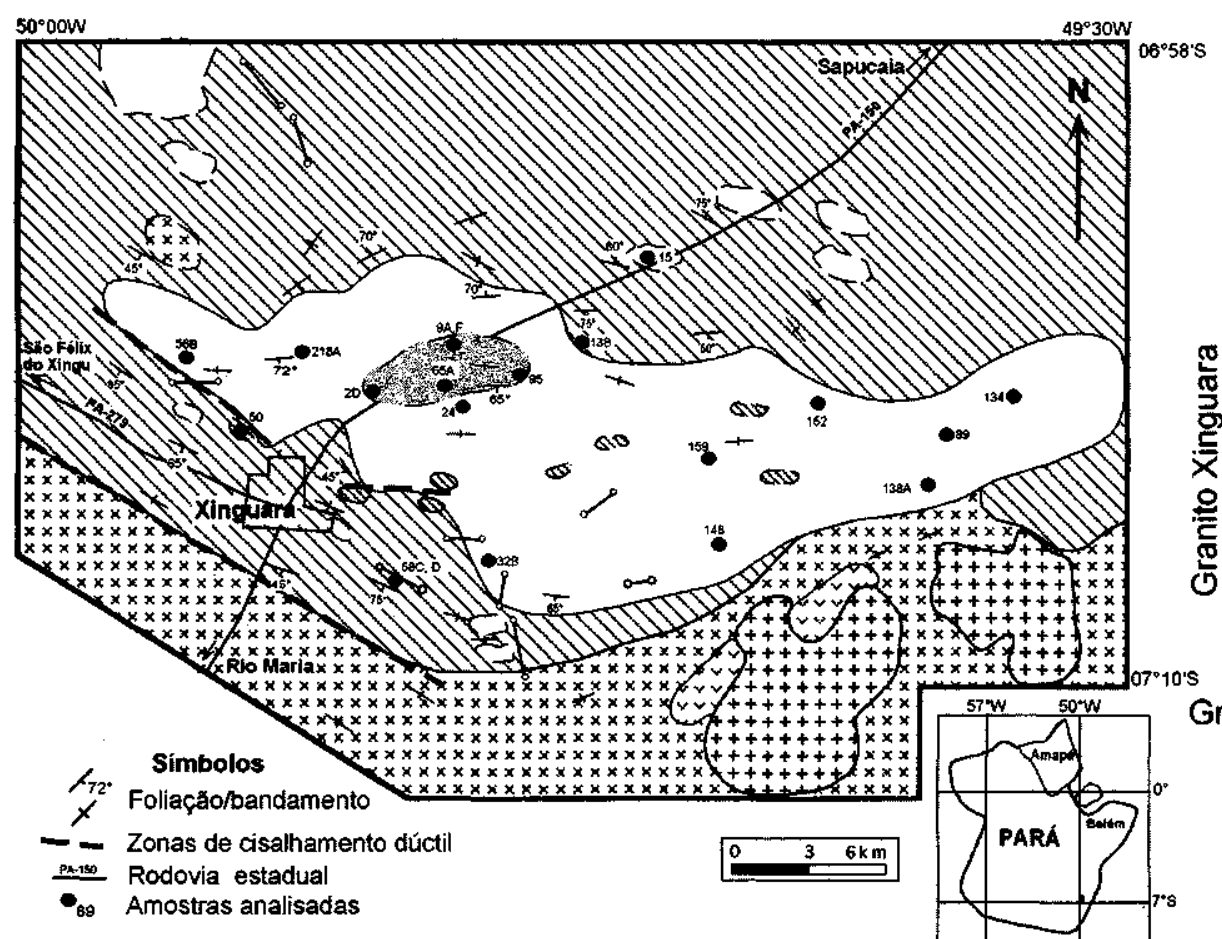

PROTEROZÓICO

Diques básicos e ácidos

Granito Manda Saia

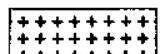

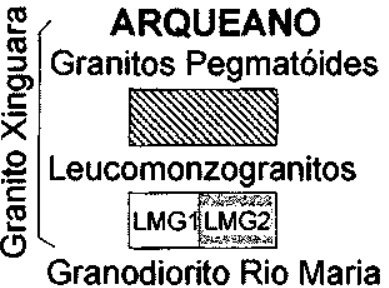

Granodiorito Rio Maria

$x \times x \times+x \times x$
$x \times x \times x \times x$

Granitóides e Gnaisses TTG

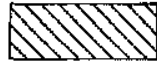

Greenstone Belt

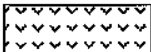

Figura l - Mapa geológico do Granito Xinguara e de localização das amostras analisadas (Leite 1995). 


\begin{tabular}{|c|c|c|c|c|c|c|c|c|c|c|c|c|}
\hline & \multicolumn{12}{|c|}{ Lemcomonzogranitos do Tipo 1 - LMG1 } \\
\hline & $2-134$ & ALt-148 & AL-15 & Al.218A & $A A_{1}-152$ & AL.89 & $\overline{A L}-138 \mathrm{~A}$ & AL-15\% & $\mathrm{L}-32 \mathrm{~B}$ & $\mathrm{~N}-24$ & NL-568 & Media \\
\hline $\mathrm{SjO}_{2}$ & 71,70 & 72,90 & 72,6 & 73,40 & 73,40 & 73,80 & 74,10 & 74,10 & 74,30 & 74,80 & 75,30 & 73,65 \\
\hline $\mathrm{TiO}_{2}$ & 0,20 & 0,15 & 0,21 & 0,16 & 0.21 & 0,12 & 0,06 & 0,12 & 0,04 & 0,11 & 0,08 & 0,13 \\
\hline $\mathrm{Al}_{2} \mathrm{O}_{3}$ & 13,90 & 13,90 & 13,3 & 13,60 & 13,60 & 14,00 & 13,90 & 13,30 & 13,60 & 12,70 & 12,80 & 13.54 \\
\hline $\mathrm{Fe}_{2} \mathrm{O}_{3}$ & 1,46 & 1.46 & 0,08 & 1,11 & 1,31 & 0,92 & 1,24 & 1,35 & 0,97 & 1,19 & 1,16 & 1,11 \\
\hline FeO & 0,71 & 0,56 & 2,45 & 0,57 & 0,86 & 0,43 & 0,07 & 0,28 & 0,21 & 0,21 & 0,14 & 0.59 \\
\hline MnO & 0,02 & 0,04 & 0,03 & 0,02 & 0,02 & 0,02 & 0.01 & 0,01 & $<0,01$ & 0,01 & 0,01 & 0,02 \\
\hline MgO & 0,45 & 0,39 & 0,42 & 0,36 & 0,60 & 0,39 & 0,05 & 0,24 & 0,05 & 0,12 & 0,10 & 0,29 \\
\hline $\mathrm{C} 2 \mathrm{O}$ & 1.44 & 1,50 & 1,3 & 1,96 & 2,23 & 1,30 & 0,86 & 1,33 & 1,29 & 0.93 & 0,99 & 1,38 \\
\hline $\mathrm{Na}_{2} \mathrm{O}$ & 3,72 & 3,70 & 3,38 & 3,96 & 4,20 & 4,10 & 3,99 & 3,66 & 3,83 & 3,60 & 3,56 & 3,79 \\
\hline $\mathbf{K}_{2} \mathrm{O}$ & 5,22 & 4,80 & 5,54 & 4,29 & 3,00 & 4,50 & 5,03 & 4,91 & 5,06 & 5,24 & 5,01 & 4,78 \\
\hline $\mathbf{P}_{2} \mathbf{O}_{3}$ & 0,18 & 0,17 & 0,2 & 0,16 & 0,17 & 0,05 & 0,14 & 0,15 & 0,15 & 0,14 & 0,14 & 0,15 \\
\hline $\mathbf{P F}$ & 0,61 & 0,69 & 0,61 & 0,45 & 0.40 & 0,39 & 0,78 & 0,92 & 0,34 & 0,40 & 0,32 & 0,54 \\
\hline Total & 99,61 & 100,26 & 100,12 & 100,20 & 100,10 & 100,02 & 100,23 & 100,37 & 99,85 & 98,45 & 99,61 & 99,97 \\
\hline$\overline{B a}$ & 1047 & 1170 & 1514 & 1125 & 589 & 851 & 755 & 916 & 981 & 920 & 484 & $\overline{941,1}$ \\
\hline $\mathbf{S r}$ & 206 & 319 & 290 & 314 & 326 & 243 & 250 & 217 & 265 & 289 & 174 & 263,0 \\
\hline $\mathbf{R b}$ & 139 & 180 & 141 & 126 & 109 & 181 & 188 & 177 & 139 & 152 & 181 & 156,0 \\
\hline $\mathbf{Z r}$ & 192 & 186 & 330 & 100 & 140 & 206 & 110 & 152 & 86 & 184 & 106 & 163,0 \\
\hline $\mathbf{Y}$ & 8 & 4 & 34 & 4 & 4 & 3 & 21 & 5 & $<1$ & 6 & 7 & 9,6 \\
\hline Nb & $<4$ & 8 & 12 & 8 & 8 & 8 & $<4$ & $<4$ & $<4$ & 8 & $<4$ & 8,6 \\
\hline Ga & 13 & 13 & 13 & 14 & 14 & 13 & 13 & 11 & $<10$ & $<10$ & 12 & 32,9 \\
\hline Th & 38 & 59 & 105 & $<5$ & 78 & 78 & 61 & 51 & $<s$ & 78 & 43 & 66,0 \\
\hline$\overline{Q z}$ & 27,14 & 29,82 & 27,22 & 29,82 & 32,46 & 29,61 & 30,29 & 31,47 & 30,49 & 32,49 & 33,79 & 28.57 \\
\hline Or & 31,17 & 28,49 & 32,91 & 25,44 & 17,80 & 26,69 & 29,89 & 29,18 & 30,06 & 31,27 & 29,82 & 30,59 \\
\hline $\mathbf{A b}$ & 31,80 & 31,45 & 28,75 & 33,62 & 35,69 & 34,82 & 33,95 & 31,15 & 32,58 & 30,76 & 30,34 & 31,21 \\
\hline $\mathrm{Na}$ & 5,88 & 6,36 & 4,79 & 7,52 & 9,44 & 6,15 & 3,37 & 5,40 & 5,01 & 3,06 & 4,03 & 5,77 \\
\hline $\mathrm{Cn}$ & & 0,30 & & - & - & 0,14 & 0,07 & . & . & 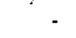 & 0,06 & - \\
\hline Di & 0,12 & & 0,33 & 0,93 & 0,43 & 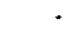 & - & 0,20 & 0,27 & 0,53 & . & 0,11 \\
\hline Hy & 1,08 & 0,98 & 5,04 & 0,47 & 1,48 & 0,97 & 0,13 & 0,51 & - & 0,06 & 0,25 & 1,06 \\
\hline $\mathrm{Ae}$ & . & - & 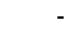 & - & - & - & & - & - & & - & - \\
\hline Ns & - & - & - & . & - & - & . & - & - & - & . & - \\
\hline Wo & - & & . & - & - & • & - & - & 0,04 & . & - & 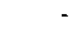 \\
\hline Ma & 1,79 & 1,51 & 0,12 & 1,44 & 1,91 & 1,11 & 0,08 & 0,59 & 0,56 & 0,39 & 0,25 & 1,99 \\
\hline |l & 0,38 & 0,29 & 0,40 & 0,30 & 0,40 & 0,23 & 0,11 & 0,23 & 0,08 & 0,21 & 0,15 & 0.23 \\
\hline $\mathrm{Hm}$ & 0.24 & 0,43 & . & 0,12 & 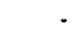 & 0,16 & 1,19 & 0,95 & 0,59 & 0,93 & 0,99 & 0,08 \\
\hline Ap & 0,40 & 0,37 & 0,44 & 0,35 & 0,37 & 0,11 & 0,31 & 0,33 & 0,33 & 0,31 & 0,31 & 0.39 \\
\hline $\bar{R} \mathbf{b} / \mathbf{S} x$ & 0,67 & 0,56 & $0, \overline{49}$ & 0,40 & 0,33 & 0,74 & 0,75 & 0,82 & 0,52 & 0,53 & $1, \overline{04}$ & 0,59 \\
\hline $\mathbf{S r} / \mathbf{B}_{\mathbf{z}}$ & 0,20 & 0,27 & 0,19 & 0.28 & 0,55 & 0,29 & 0.33 & 0,24 & 0,27 & 0,31 & 0,36 & 0,28 \\
\hline $\mathrm{Pe}_{2} \mathrm{O}_{3} / \mathrm{Fe}$ & 2,06 & 2,61 & 0,03 & 1,95 & 1,52 & 2,14 & 17,71 & 4,62 & 4,62 & 5,67 & 8,29 & 1,89 \\
\hline $\mathrm{K}_{2} \mathrm{O} / \mathrm{Na}_{2} \mathrm{O}$ & 1,40 & 1,30 & 1,64 & 1,08 & 0,71 & 1,11 & 1,26 & 1,34 & 1,32 & 1,46 & 1,41 & 1,26 \\
\hline
\end{tabular}

\begin{tabular}{|c|c|c|c|c|c|c|c|c|c|c|c|c|c|}
\hline & \multicolumn{6}{|c|}{ Leweomonzogranitos do Tipo $2-\mathrm{LMC2}$} & \multicolumn{3}{|c|}{ Lencosienogranitos } & \multicolumn{3}{|c|}{ Granitos Pegmatódides } & \multirow{2}{*}{$\begin{array}{c}\text { Media } \\
\text { Gerat } \\
\end{array}$} \\
\hline & & N1-95 & & & & & & & & $A 1-50$ & 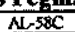 & Media & \\
\hline $\mathrm{SiO}_{2}$ & 72,50 & 72,50 & 72,90 & 73,10 & 73.90 & 72.98 & 74,70 & $\frac{-20}{74,90}$ & 74,8 & 75,00 & 7520 & 75,1 & \\
\hline $\mathrm{TiO}_{2}$ & 0,14 & 0,12 & $0,1 \mathrm{k}$ & 0,11 & 0,15 & 0,13 & 0,01 & 0,09 & 0,05 & 0,06 & 0,04 & 0,05 & 0,11 \\
\hline $\mathrm{Al}_{2} \mathrm{O}_{3}$ & 13,60 & 13,80 & 13,40 & 13,60 & 12,50 & 13,38 & 12,60 & 13,30 & 12,95 & 12,90 & 12,90 & 12,9 & 13.38 \\
\hline $\mathrm{O}_{3}$ & 1,50 & 1,41 & 1,57 & 1,28 & 1,45 & 1,44 & 0,79 & 1,19 & 0,99 & 0,81 & 0,94 & 0,98 & 1,16 \\
\hline Feo & 0,34 & 0,42 & 0,36 & $0,56$. & 0,35 & 0,41 & 07 & 21 & 0,14 & 07 & 0,14 & 0,11 & 0,45 \\
\hline Ino & 0,01 & 0,01 & 0,01 & 0,01 & 0,02 & 0,01 & 00,01 & 0,01 & 0,01 & 0,00 & 0,01 & 40,01 & 0,01 \\
\hline$[\mathrm{gO}$ & 0,25 & 0,25 & 0,28 & 0,26 & 0,22 & 0,25 & $\leqslant 0,01$ & 0,17 & 0,09 & 11 & 0,04 & 0,08 & 25 \\
\hline 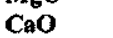 & 1,15 & 1,23 & 1,00 & 0,68 & 0,93 & 1,00 & 14 & 40 & 0,77 & 98 & 0,66 & 0,82 & 17 \\
\hline 0 & $3 x$ & 3,1 & & 3.06 & 2,93 & 3,10 & a & 38 & 2,64 & & 3,22 & 3,67 & 49 \\
\hline & 6,29 & 6,57 & 6,54 & 6,69 & 6,41 & 6.50 & 23. & 4,64 & 6,94 & 42 & 6,25 & 5,34 & 48 \\
\hline$P_{2} \mathrm{C}$ & 0,16 & 0,16 & 0,16 & 0,17 & 0,16 & 0,16 & 14 & 0,14 & 0,14 & 12 & 0,13 & 0,13 & 15 \\
\hline $\mathbf{P F}$ & 0,51 & 0,60 & 0,62 & 0,64 & 0,31 & 0,54 & 0,30 & 0,50 & 0,40 & 0,39 & 0,40 & 0,40 & 8,51 \\
\hline Tota & 99,74 & $\overline{100,24}$ & 100,01 & 100,16 & 99,33 & 99,96 & 99,88 & 99,93 & $99, \overline{91}$ & 99,98 & 99,93 & 99,46 & 100,04 \\
\hline B & 87 & 95 & 1330 & 1007 & 706 & 993 & 2367 & 27 & 2555 & 9 & 1010 & 764 & 1697,8 \\
\hline & 300 & 231 & 281 & 216 & 192 & 244 & 323 & 403 & 363 & 150 & 222 & 186 & 260.55 \\
\hline $\mathrm{kb}$ & 198 & 175 & $1 t$ & 19 & 211 & 193 & 24 & 11 & 158 & 89 & 183 & 136 & 163,4 \\
\hline & 256 & 198 & 200 & 244 & 216 & 223 & 49 & $5 s$ & 52 & 71 & 73 & 72 & 57.7 \\
\hline & 11 & 4 & 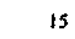 & 6 & If & 9,4 & $\Leftrightarrow$ & 4 & $<1$ & 5 & 20 & 12 & 9,87 \\
\hline $\mathrm{Nb}$ & $s$ & $<4$ & $<4$ & $<4$ & 9 & 7 & $<4$ & $<4$ & 4 & 8 & $<4$ & 6 & 813,00 \\
\hline Ga & 11 & $<10$ & $<10$ & $<10$ & $<10$ & $<0$ & $<10$ & $<10$ & $<10$ & 13 & $<10$ & $<13$ & 12,38 \\
\hline Th & 94 & 90 & 90 & 57 & 77 & 81,6 & 9 & $<5$ & 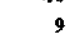 & 21 & $<5$ & 21 & 59.52 \\
\hline & 27,3 & $\overline{26}$ & 28 & 28,47 & 31,10 & 28,32 & 28.99 & 34,83 & 31,69 & $\overline{32}$ & 31,62 & $\overline{2,21}$ & $\overline{0,42}$ \\
\hline & 37 & 38 & 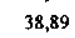 & 39 & 38,26 & 38,68 & 8 & a & 41,16 & 0 & 37,12 & 31,81 & 2,57 \\
\hline A & 28,06 & 26,93 & 26,0 & 26,02 & 25,04 & 26,41 & 13,50 & 28,77 & 22,45 & 35,37 & 27,38 & $3 \ell, 36$ & 29,67 \\
\hline A & 3.80 & 4,05 & 3,54 & 2.2 & 2,05 & 3,45 & & 6,07 & 2,92 & 3,71 & 2,31 & 3,42 & 4,73 \\
\hline C & & & & 0.50 & 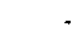 & & & 0.51 & 0.04 & - & & &, 01 \\
\hline & 0.7 & $\theta$ & 0 & & 1,19 & 0.36 & . & 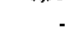 & & 33 & 10 & 0,23 & \\
\hline $\mathrm{Hy}$ & 0,30 & 0.25 & 0,56 & 0,65 & . & 0.46 & 0,16 & 0,43 & 0.23 & 0,12 & 0,05 & 0,07 & 0,58 \\
\hline$\cdots$ & & & & & - & & 2,30 & & & . & & & . \\
\hline & - & - & * & . & & & 1 & + & & - & & & . \\
\hline $\mathbf{v}$ & & & & 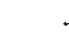 & 0,01 & & - & & & . & & & \\
\hline & 0. & & & & & 5 & - & 15 & 34 & 05 & 37 & 18 & 11 \\
\hline II & 0,2 & 0 & 0 & & 0,29 & 0,25 & 0,02 & & 0,10 & & 18 & 10 & 21 \\
\hline $\mathrm{Hm}$ & 1, & 0 & & & & & 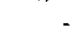 & & 0,76 & & & 776 & 47 \\
\hline Ap & 0,35 & 0,35 & 0,35 & 0,37 & 0,35 & 0,35 & 0,31 & 0,31 & $0 ; 31$ & 0,27 & 0,29 & 0,26 & 0,31 \\
\hline & $0, \overline{6}$ & 0,7 & $\overrightarrow{0,6}$ & & 1,79 & 6,79 & 0,6 & $\overline{0,2}$ & 9.44 & & 0,82 & $\overline{\mathbf{6 . 7 3}}$ & 64 \\
\hline & & & & & & & & & & & & & 25 \\
\hline & 4,4 & 3,3 & 4,36 & 2,29 & 4,14 & 1,55 & 11,29 & 5,6 & 7,07 & 11,57 & 6,71 & 8,33 & 4,47 \\
\hline $\mathrm{K}>\mathrm{O}$ & 1,91 & 2,07 & 2,14 & 2,19 & 2,19 & 2,10 & 4,86 & i,37 & 2,63 & 1,07 & 1,94 & 1,45 & 1,63 \\
\hline
\end{tabular}



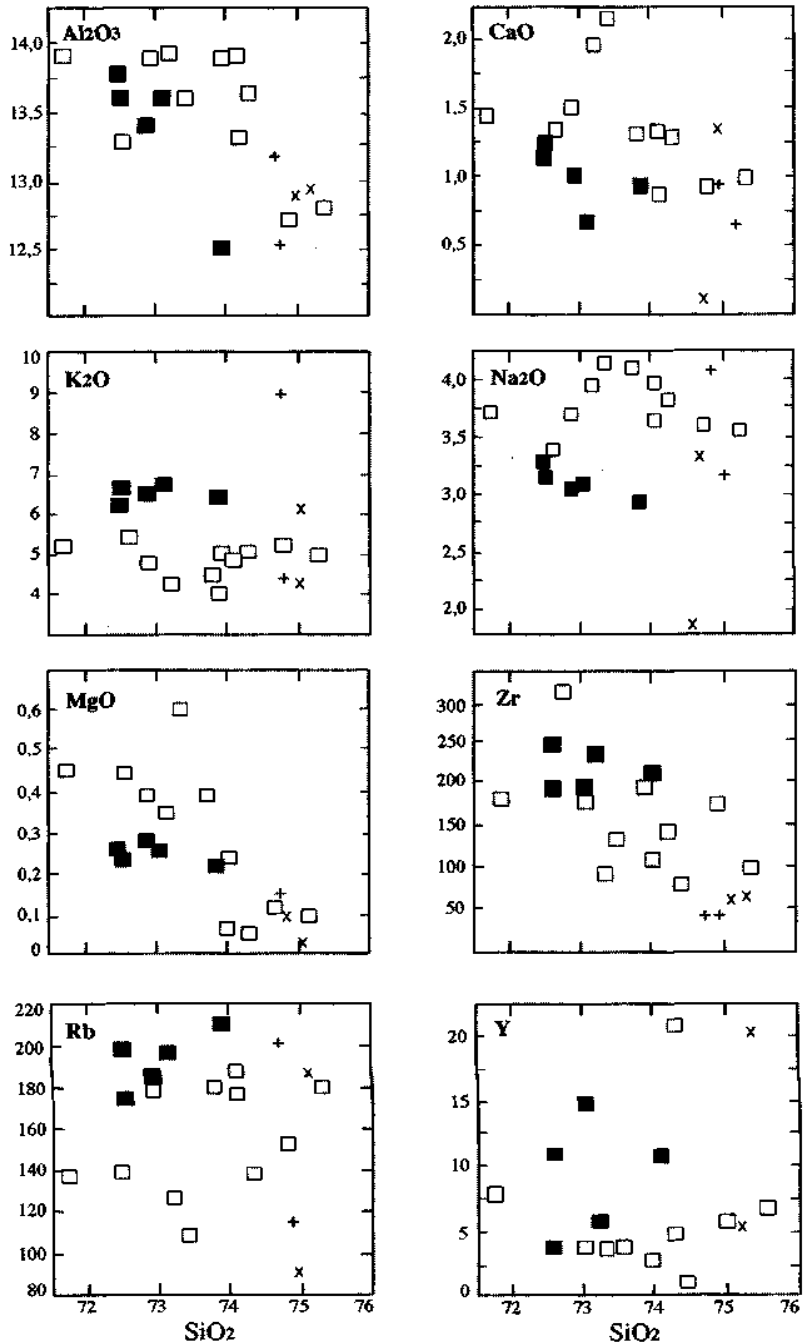

Leucomonzogranitos do tipo 1 (LMG1) x Granitos Pegmatóides

- Leucomonzogranitos do tipo 2 (LMG2) + Leucisienogranitos

Figura 2 - Diagramas de Harkerpara os leucogranitos Xinguara.

Os sienogranitos e granitos pegmatóides tendem a ser mais ricos em $\mathrm{SiO}_{2}$ do que os leucomonzo grani tos. Os dois primeiros apresentam baixos valores dos óxidos concentrados nas fases máficas e em $\mathrm{CaO}$, sugerindo a sua derivação a partir de líquidos resultantes de um fracionamento intenso, explicável tanto por cristalização fracionada, quanto por graus de fusão parcial muito baixos. Geralmente, não divergem muito em composição dos leucomonzogranitos de mesmos teores de $\mathrm{SiO}_{2}$ (Fig. 2). Como o número de análises dos leuco-sienogranitos e granitos pegmatóides foi reduzido não ficam muito claras as possíveis diferenças existentes entre eles.

De acordo com o índice de Shand, o Granito Xinguara mostra características metaluminosas e peraluminosas. Nas composições normativas C.I.P.W. (Tab. 1) das diferentes fácies do Granito Xinguara constata-se a presenca ora de coríndon normativo, ora de diopsídio normativo. $\mathrm{O}$ coríndon normativo aparece sempre com percentuais inferiores à unidade e está ausente na fácies granito pegmatóide. Os teores de diopsídio normativo também são muito baixos, superando levemente a unidade em apenas uma amostra. Conclui-se que a maioria das amostras é ligeiramente metaluminosa e que o Granito Xinguara varia de metaluminoso a ligeiramente peraluminoso.

Comportamento de $\mathbf{R b}, \mathrm{Sr}$ e Ba O comportamento dos elementos litófilos é muito importante para esclarecer a evolução de rochas leucograníticas, pois a distribuição destes elementos é ampla-
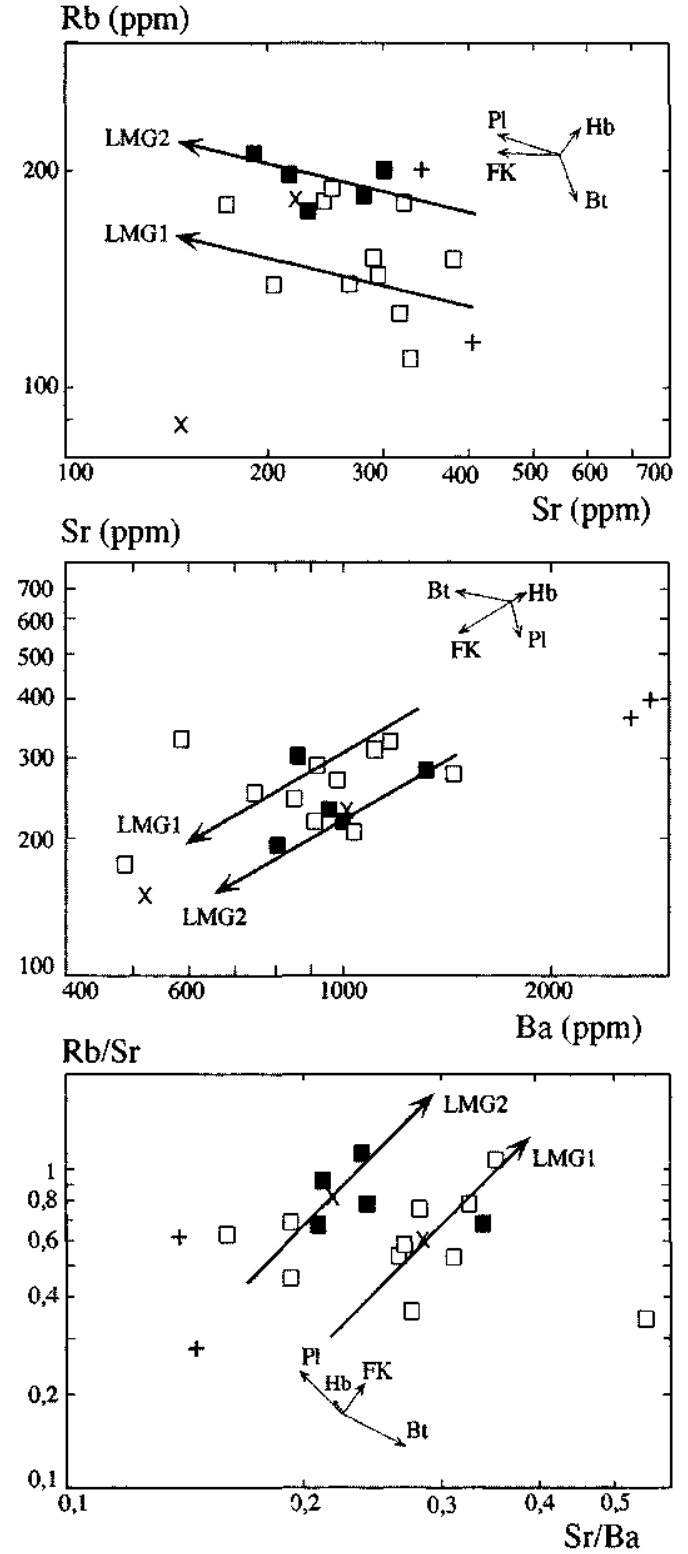

Figura 3 - Diagramas Rb vs. Sr, Sr vs. Ba e Rb/Sr vs. Sr/Ba para as amostras do Granito Xinguara. Os vetares indicam a influência do fracionamento do plagioclásio (PI), feldspato potássico (FK), hornblenda $(\mathrm{Hb})$ e biotita (Bt) na composição do líquido residual. Símbolos conforme Figura 2.

mente controlada pelas fases minerais dominantes nestas rochas, com destaque para os feldspatos. É sabido igualmente que o comportamento geoquímico de elementos-traço compatíveis e incompatíveis constitui um bom indicador dos processos petrogenéticos (Hanson 1989). Em razão disso, foram elaborados os diagramas $\mathrm{Rb}-\mathrm{Sr}, \mathrm{Sr}-\mathrm{Ba}$ e $\mathrm{Rb} / \mathrm{Sr}-$ $\mathrm{Sr} / \mathrm{Ba}$ das amostras estudadas (Fig. 3), nos quais foram indicados os sentidos de variações das composições dos líquidos em função do fracionamento de determinadas fases minerais (plagioclásio, feldspato potássico, hornblenda e biotita).

Nos diagramas mencionados, constata-se a existência de dois trenas subparalelos definidos, um deles, pela maioria das amostras dos LMG1 e, o segundo, por aquelas do LMG2. Tais trenas são fortemente controlados pelo fracionamento de feldspato potássico, porém ao que tudo indica, a influência de plagioclásio e biotita foi igualmente importante. Outro aspecto digno de nota é a variação moderada dos teores dos elementos-traço considerados, bem como das razões $\mathrm{Rb} / \mathrm{Sr}$ (Tab. 1; Fig. 3). Tal fato, aliado à comparação entre os diagramas mencionados acima com diagramas semelhantes elaborados para o granitos proterozóicos Jamon, Musa e diques associados, nos quais processos de cristalização fracionada foram considerados muito efetivos durante a evolução magmáticadas fácies graníticas (Dali'Ag- 

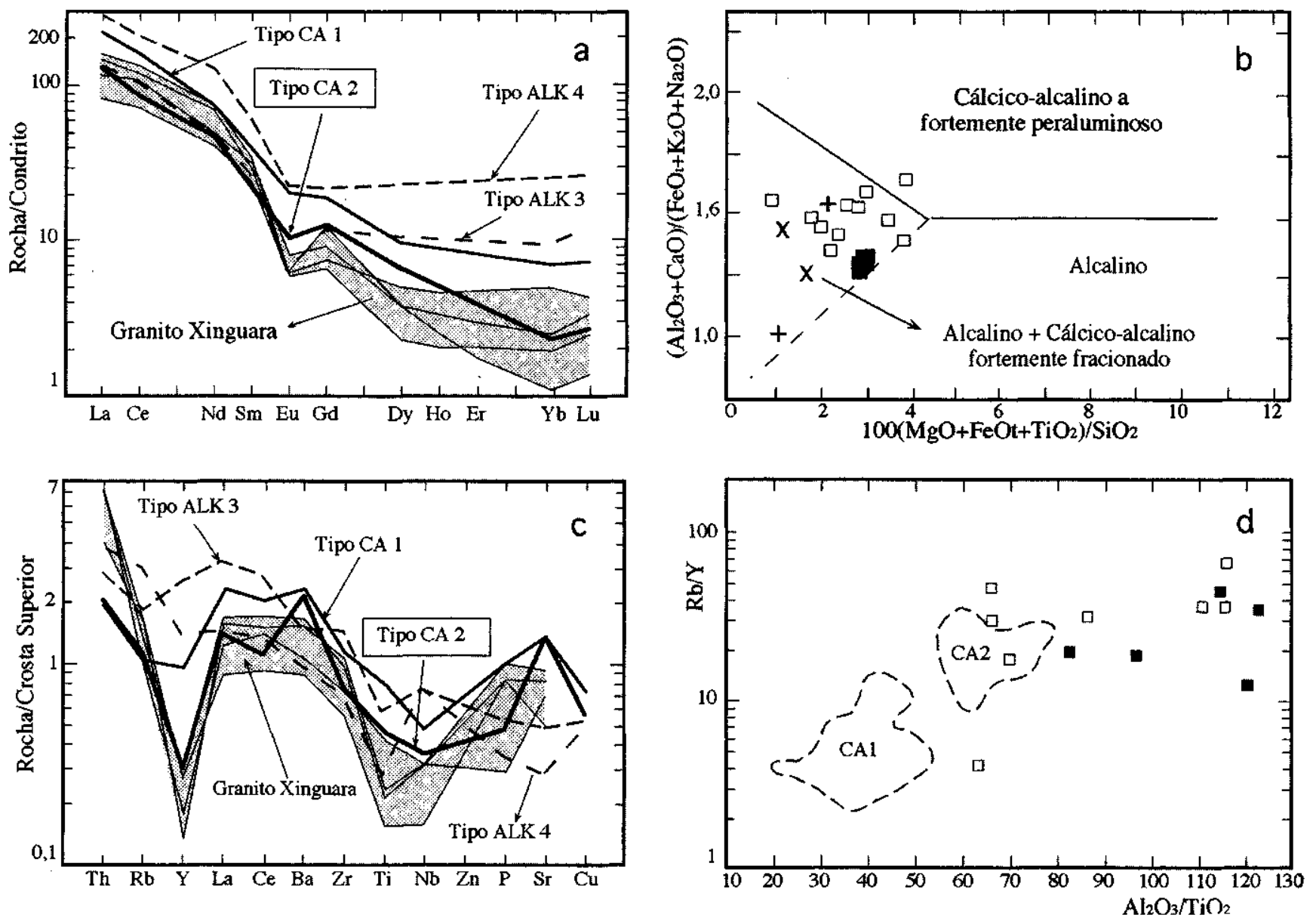

Figura 4-Diagramas geoquímicos para os leucomonzogranitos Xinguara. (a) Padrões de Elementos Terras Raras para os LMGl, normalizados segundo Anders \& Grevesse (1989); CAI e CA2 granitos cálcio-alcalinos l e 2; ALK3 e ALK4: leucogranitos alcalinos 3 e 4 (Sylvester 1994) (b) Diagrama $\left(\mathrm{Al}_{2} \mathrm{O}_{3}+\mathrm{CaO}\right) /\left(\mathrm{FeO}+\mathrm{Na}_{2} \mathrm{O}+\mathrm{K}_{2} \mathrm{O}\right)$ vs. 100( $\left.\mathrm{MgO}+\mathrm{FeO}_{t}+\mathrm{TiO}_{2}\right) / \mathrm{SiO}_{2}$ (Sylvester 1989); (c) Diagrama de multi-elementos para os LMG1, normalizados em relação à crosta continental superior (Taylor \& McLennan 1985); e (d) Diagrama $\mathrm{Rb} / \mathrm{Y}$ vs. $\mathrm{Al}_{2} \mathrm{O}_{3} / \mathrm{TiO} \mathrm{O}_{2} \mathrm{para}$ os $\mathrm{LMGl}$ e LMG2. Campos CAI e CA2, cf. Sylvester (1994). Símbolos como na Figura 2.

nol et al. 1999), indica - seguindo as evidências sugeridas por Hanson (1989) - que, durante a génese dos magmas formadores do Granito Xinguara, os processos de cristalização fracionada também aluaram, porém, de forma comparativamente mais moderada. Isso é, em parte, consequência do caráter extremamente félsico dos magmas formadores do granito estudado.

Por outro lado, os comportamentos distintos dos LMGl e LMG2, tanto nos diagramas de Harker (Fig. 2), quanto naqueles baseados nos elementos litófilos (Fig. 3), sugerem ser mais razoável admitir, neste estágio, que esses dois grupos de granitos cristalizaram a partir de dois líquidos distintos.

Elementos Terras Raras Foram analisadas quatro amostras de LMGl para elementos terras raras (Tab. 2), sendo os dados normalizados em relação ao condrito conforme os valores de Anders \& Grevesse (1989). Os padrões de elementos terras raras (Fig. 4a) mostram enriquecimento acentuado dos terras raras leves (ETRL) em relação aos terras raras pesados (ETRP), indicando que houve acentuado a moderado fracionamento dos ETRP, conforme revelam as razões $(\mathrm{La} / \mathrm{Yb})_{\mathrm{n}},(\mathrm{Tab} .2)$. Estas variam de 149,07 a 16,63 mostrando que o fracionamento de fases enriquecidas em ETRP foi bastante diversificado de uma amostra para outra e que o conjunto de amostras analisadas apresenta algumas diferenças, embora o padrão geral seja mantido. As razões $(\mathrm{La} / \mathrm{Sm})_{n}$ e $(\mathrm{Dy} / \mathrm{Yb})_{n}$ variam de 3,39 a 5,13 e de 1,01 a 3,5 , respectivamente, mostrando que o fracionamento interno dos terras raras leves e pesados não foi muito acentuado, sendo mais expressivo nos ETRL.

A presença constante de expressivas anomalias negativas de Eu, com razões ( $\left(\mathrm{Eu} / \mathrm{Eu}^{*}\right)$ variando entre 0,28 e 0,38 , é outra feição notável das amostras analisadas. Ela revela uma participação efetiva de pla-
Tabela 2 - Análises de elementos terras raras dos leucomonzogranitos do tipo l do Granito Xinguara.

\begin{tabular}{|l|rrrr|r|}
\cline { 2 - 6 } \multicolumn{1}{c|}{} & \multicolumn{5}{c|}{ Leucomonzogranitos do Tipo 1 } \\
\cline { 2 - 6 } \multicolumn{1}{c|}{} & AL-152 & AL-89 & AL-24 & AL-56B & Média \\
\hline $\mathrm{La}$ & 36,99 & 47,47 & 51,36 & 26,16 & 40,49 \\
$\mathrm{Ce}$ & 89,23 & 97,23 & 110,40 & 59,12 & 88,99 \\
$\mathrm{Nd}$ & 30,07 & 43,22 & 45,75 & 25,00 & 36,01 \\
$\mathrm{Sm}$ & 6,32 & 5,80 & 6,81 & 4,83 & 5,94 \\
$\mathrm{Eu}$ & 0,60 & 0,44 & 0,49 & 0,45 & 0,49 \\
$\mathrm{Gd}$ & 2,47 & 1,77 & 3,22 & 1,99 & 2,36 \\
$\mathrm{Dy}$ & 1,29 & 0,76 & 1,25 & 1,65 & 1,23 \\
$\mathrm{Ho}$ & 0,25 & 0,15 & 0,19 & 0,34 & 0,23 \\
$\mathrm{Er}$ & 0,64 & 0,45 & 0,38 & 1,02 & 0,62 \\
$\mathrm{Yb}$ & 0,55 & 0,43 & 0,24 & 1,09 & 0,57 \\
$\mathrm{Lu}$ & 0,11 & 0,08 & 0,04 & 0,14 & 0,09 \\
\hline$(\mathrm{La} / \mathrm{Yb})_{\mathrm{n}}$ & 46,75 & 76,70 & 149,07 & 16,63 & 49,38 \\
$(\mathrm{La} / \mathrm{Sm})_{\mathrm{n}}$ & 3,66 & 5,13 & 4,72 & 3,39 & 4,27 \\
$\left(\mathrm{Dy} / \mathrm{Yb}_{\mathrm{n}}\right.$ & 1,57 & 1,18 & 3,50 & 1,01 & 1,44 \\
$\mathrm{Eu} / \mathrm{Eu}^{*}$ & 0,38 & 0,32 & 0,28 & 0,37 & 0,33 \\
\hline
\end{tabular}

gioclásio + feldspato potássico no fracionamento, seja retidos no resíduo de fusão de uma rocha fonte crustal, seja como fases que sofreram um fracionamento importante durante a cristalização.

O acentuado empobrecimento dos ETRP pode ter sido causado por fracionamento de granada, anfibólio, zircão e piroxênios, fases mine- 
rais que concentram notavelmente os ETRP. Pode-se, portanto, admitir, preliminarmente, que uma ou mais destas fases foram retidas no resíduo de fusão, pois o seu fracionamento durante a evolução magmática parece muito improvável. Dentre elas, o fracionamento de granada e/ou anfibólios parece bem mais provável que o de piroxênios, tendo em vista que os primeiros concentram $\mathrm{Y}$, elemento cujos teores são muito baixos nos leucogranitos Xinguara. Quanto ao zircão, os teores moderados deste elemento nos leucogranitos fortalecem a hipótese de um fracionamento expressivo deste mineral.

Caracterização da Série Geoquímica Embora a utilização isolada dos diagramas de Pearce et al. (1984) não permita definir o ambiente tectônico de colocação de rochas granitóides, pois sabe-se que há granitóides geoquimicamente similares, formados em ambientes tectônicos distintos (Sylvester 1989), os mesmos podem auxiliar na caracterização geoquímica das rochas estudadas, permitindo a eliminação de determinadas hipóteses. As amostras do Granito Xinguara situam-se no limite dos campos dos granitos sin-colisionais e de arcos vulcânicos de Pearce et al. (1984) porém os LMG2, devido ao seu enriquecimento relativo em $\mathrm{Rb}$, tendem a adentrar no campo dos granitos sin-colisionais.

Sylvester (1989) propõe a utilização do diagrama $\left(\mathrm{Al}_{2} \mathrm{O}_{3}+\mathrm{CaO}\right) /$ $\left(\mathrm{FeO}_{\mathrm{t}}+\mathrm{Na}_{2} \mathrm{O}+\mathrm{K}_{2} \mathrm{O}\right)$ versus. $100\left(\mathrm{MgO}+\mathrm{FeO}_{\mathrm{t}}+\mathrm{TiO}_{2}\right) / \mathrm{SiO}_{2} \quad$ (Fig. $\left.4 \mathrm{~b}\right)$ para verificar a natureza das séries magmáticas de rochas granitóides, admitidas como sin-colisionais. Neste diagrama, as amostras do Granito Xinguara concentram-se no campo onde se superpõem os granitóides alcalinos e os cálcio-alcalinos fortemente fracionados, porém as características geoquímicas do Granito Xinguara, tais como os baixos conteúdos de $\mathrm{Zr}, \mathrm{Y}$ e $\mathrm{Nb}$, e o acentuado a moderado fracionamento de ETRP, sugerem sua maior afinidade com os últimos.

As características geoquímicas do Granito Xinguara sugerem, em princípio, maiores analogias com os granitos cálcio-alcalinos, similares aos de ambientes sin-colisionais e de arcos vulcânicos fanerozóicos. Porém, os dados apresentados não são totalmente conclusivos, pois a convergência geoquímica, típica de leucogranitos ricos em sílica (Chappell \& White 1992), dificulta a identificação da série geoquímica a que pertencem os granitos estudados. Essa questão foi aprofundada por Sylvester (1994) que distinguiu, com ênfase em geoquímica, diferentes grupos de leucogranitos arqueanos - cálcio-alcalinos, fortemente peraluminosos e alcalinos. Procurou-se, em razão disso, estabelecer comparações entre o Granito Xinguara e tais grupos de leucogranitos arqueanos.

Conforme se pode perceber pelos itens precedentes, as características mineralógicas e geoquímicas das rochas estudadas são inteiramente distintas daquelas observadas nos leucogranitos fortemente peraluminosos. Isso permite afastar a hipótese de que as mesmas correspondam a esse grupo de granitos, restando a considerar as alternativas de que elas sejam cálcio-alcalinas ou alcalinas. Sylvester (1994) dividiu cada um dos grupos de leucogranitos em dois subgrupos, os quais serão a seguir comparados com os LMG1 de Xinguara. As composições químicas médias dos vários granitos são fornecidas na Tabela 3.

Os padrões de elementos terras raras (Fig. 4a) mostram claramente uma maior afinidade geoquímica entre os LMG1 de Xinguara e a composição média dos leucogranitos cálcio-alcalinos do tipo 2 (CA2) de Sylvester (1994). Os mesmos se assemelham sobretudo pelo acentuado fracionamento de ETRP (Cf. valores de $\mathrm{La}_{\mathrm{n}} / \mathrm{Yb}_{\mathrm{n}}$; Tab. 1), pela presença de expressiva anomalia negativa de $\mathrm{Eu}$ (mais acentuada, porém, no Granito Xinguara) e pelo enriquecimento em ETRL. A principal diferença entre os LMG1 de Xinguara e os leucogranitos cálcio-alcalinos do tipo 1 (CAI) e os tipos alcalinos 3 e 4 (ALK3 e ALK4) de Sylvester consiste na ausência nos últimos de empobrecimento significativo em ETRP, refletida nos seus padrões subhorizontais para os ETRP (Fig. 4a). Constata-se, no entanto, que a amostra AL-56B, com a menor razão $\mathrm{La}_{n} / \mathrm{Yb}_{\mathrm{n}}$ do conjunto estudado (Tab. 1), tende a apresentar um padrão um pouco mais próximo daqueles dos referidos granitos (Fig. 4a).

No diagrama de multi-elementos (Fig. 4c), normalizado em relação à crosta continental superior média (Taylor \& McLennan 1985; cf. Sylvester 1994), as amostras dos LMG1 do Granito Xinguara apresentam um comportamento análogo ao dos leucogranitos cálcio-alcalinos e bem distinto daqueles dos tipos alcalinos. O leucogranito Xinguara diverge dos últimos por apresentar acentuadas anomalias negativas de $\mathrm{Y}$, Ti e $\mathrm{Nb}$, bem como enriquecimento relativo em $\mathrm{P}$ e Sr e empobrecimento em La e Ce. Os padrões dos granitos CAI e CA2 são bastante similares, mas os CA2 exibem anomalias negativas de $\mathrm{Y}$, Ti e Nb mais acentuadas, verificando-se o mesmo no leucogranito Xinguara. Isso

reforça as analogias entre este e os leucogranitos CA2 assinaladas anteriormente.

DISCUSSÕES Petrogênese Qualquer discussão sobre a petrogênese do Granito Xinguara é limitada por não se dispor de dados isotópicos. Entretanto, algumas ideias preliminares merecem ser assinaladas. O Granito Xinguara apresenta uma notável homogeneidade composicional, conforme indicam os dados petrográficos e geoquímicos. Chama a atenção a natureza granítica e hololeucocrática das diferentes variedades de rochas do corpo, com altos teores de $\mathrm{SiO}_{2}$ $(>71,5 \%)$ e álcalis (média de 8,95\%), elevadas razões $\mathrm{K}_{2} \mathrm{O} / \mathrm{Na}_{2} \mathrm{O}$ (média de 1,57$)$, e teores médios baixos de $\mathrm{MgO}(0,23 \%)$ e moderados de $\mathrm{CaO}(1,13 \%)$. Os padrões de elementos terras raras revelam anomalias significativas de $\mathrm{Eu}$, indicando um fracionamento expressivo de feldspatos e, mais particularmente, de plagioclásio, durante a geração ou evolução do magma granítico.

Os contrastes geoquímicos observados entre os LMG1 e LMG2 indicam uma certa complexidade na origem do magma gerador do Granito Xinguara. Tais contrastes não podem ser explicados somente por processos de diferenciação magmática, tendo em vista que os dois grupos apresentam teores de $\mathrm{SiO}_{2}$ superpostos e não seguem o mesmo trend de diferenciação (Fig. 2). Issso é reforçado pelo comportamento dos elementos litófilos (Fig. 3). É pouco provável, portanto, que os dois tipos de leucomonzogranitos tenham se formado a partir de um mesmo magma parental, apesar de sua aparente associação no espaço e no tempo, a menos que se admita a possibilidade de contaminação em graus variáveis do magma original pelas rochas encaixantes, presentes no interior do corpo sob a forma de enclaves (Leite 1995). A contaminação através dos granitóides TTG não poderia, no entanto, justificar a passagem dos LMG1 para os LMG2, mais potássicos e algo mais alcalinos do que os LMG1. Por outro lado, a contaminação

Tabela 3 - Composições químicas médias do Granito Xinguara e dos leucogranitos cálcio-alcalinos e alcalinos de Sylvester (1994).

\begin{tabular}{|c|c|c|c|c|c|c|}
\hline & LMGI & LMG2 & $\mathrm{CA} 1$ & CA2 & ALK3 & ALK4 \\
\hline$\overline{\mathrm{SiO}_{2}}$ & 73,65 & 72,98 & 70,00 & 71,88 & 73,33 & 74,20 \\
\hline $\mathrm{TiO}_{2}$ & 0,13 & 0,13 & 0,40 & 0,23 & 0,29 & 0,14 \\
\hline $\mathrm{Al}_{2} \mathrm{O}_{3}$ & 13,54 & 13,38 & 14,63 & 14,69 & 13,08 & 13,52 \\
\hline $\mathrm{FeO}_{4}$ & 1.70 & 1,48 & 2,72 & 1,65 & 2,35 & 1,32 \\
\hline $\mathrm{MnO}$ & 0,02 & 0,01 & 0,05 & 0,03 & 0,04 & 0,04 \\
\hline $\mathrm{MgO}$ & 0,29 & 0,25 & 0,74 & 0,48 & 0,39 & 0,23 \\
\hline $\mathrm{CaO}$ & 1,38 & 0,99 & 2.28 & 1,69 & 1,21 & 0,94 \\
\hline $\mathrm{Na}_{2} \mathrm{O}$ & 3,79 & 3,10 & 3,89 & 4,45 & 3,26 & 3,74 \\
\hline $\mathrm{K}_{2} \mathrm{O}$ & 4,78 & 6,5 & 3,58 & 3,69 & 4,78 & 4,68 \\
\hline $\mathrm{P}_{2} \mathrm{O}_{5}$ & 0,15 & 0,16 & 0,17 & 0,08 & 0,09 & 0,06 \\
\hline LOI & 0,54 & 0,53 & 0,78 & 0,81 & 0,55 & 0,75 \\
\hline $\mathrm{Ba}$ & 941 & 993 & 1300 & 1210 & 830 & 505 \\
\hline $\mathrm{Sr}$ & 263 & 244 & 479 & 455 & 172 & 102 \\
\hline Rb & 156 & 193 & 117 & 125 & 211 & 339 \\
\hline $\mathrm{Zr}$ & 163 & 223 & 218 & 142 & 276 & 134 \\
\hline $\mathrm{Nb}$ & 8 & 7 & 12 & 9 & 19 & 19 \\
\hline $\mathrm{Y}$ & 9 & 9 & 21 & $7 \pm$ & 58 & 31 \\
\hline $\mathrm{Th}$ & 66 & 81 & 21 & 22 & 29 & 41 \\
\hline $\mathrm{Ga}$ & 12 & $<10$ & 18 & 17 & 16 & 20 \\
\hline $\mathrm{La}$ & 40,49 & - & 71 & 42 & 98 & 44 \\
\hline $\mathrm{Ce}$ & 88,99 & - & 133 & 71) & 179 & 86 \\
\hline $\mathrm{Nd}$ & 36,01 & - & 45 & 29 & 81 & 28 \\
\hline $\mathrm{Sm}$ & 5,94 & $=$ & 7,80 & 4,4 & 12 & 5,3 \\
\hline Eu & 0,49 & $=$ & 1,56 & 0,7 & 1,6 & 0,45 \\
\hline $\mathrm{Gd}$ & 2,36 & $=$ & 5,10 & 3,4 & 5,4 & 3,0 \\
\hline $\mathrm{Tb}$ & - & - & 0,73 & 0,41 & 1,8 & 0,85 \\
\hline Dy & 1,23 & - & 3,20 & 2,2 & & 3,1 \\
\hline $\mathrm{Yb}$ & 0,57 & - & 1,55 & 0.51 & 5,5 & 1,9 \\
\hline Lu & 0,09 & $\cdot$ & 0.24 & 0,09 & 0,83 & 0,37 \\
\hline $\mathrm{Al}_{2} \mathrm{O}_{3} / \mathrm{TiO}_{2}$ & 104,15 & 102,92 & 36,57 & 63.86 & 45,10 & 96,57 \\
\hline $\begin{array}{l}\mathrm{Rb} / \mathrm{Y} \\
(\mathrm{La} / \mathrm{Yb})_{\mathrm{n}}\end{array}$ & $\begin{array}{l}16,25 \\
49,38\end{array}$ & $\begin{array}{r}25.21 \\
-\end{array}$ & $\begin{array}{r}5.57 \\
38\end{array}$ & $\begin{array}{r}17,85 \\
80\end{array}$ & $\begin{array}{r}3,63 \\
24\end{array}$ & $\begin{array}{r}10.93 \\
22\end{array}$ \\
\hline $\mathrm{Eu} / \mathrm{E} \mathrm{u}^{*}$ & 0,33 & - & 0,73 & 0,73 & 0,46 & 0,36 \\
\hline
\end{tabular}


dificilmente poderia ter se dado no sentido inverso, uma vez que os LMG2 têm distribuição relativamente limitada no corpo e seria pouco provável que as rochas contaminadas, no caso os LMG1, ocupassem uma maior área. Há, ainda, enclaves de rochas ricas em clorita e moscovita no corpo granítico (Leite 1995), porém as mesmas não parecem possuir composições químicas adequadas para justificar uma contaminação capaz de explicar as variações geoquímicas observadas entre os LMG1 e LMG2. É mais razoável, portanto, admitir que os LMG1 e LMG2 tenham se originado a partir de líquidos distintos que evoluíram independentemente.

Segundo Ridley (1992) este tipo de magma seria formado em altos níveis crustais, representando o último e maior evento ígneo dos crátons arqueanos. Ele admite duas origens para tais líquidos graníticos: (i) fusão parcial de granitóides e gnaisses TTG, ou (ii) a partir da cristalização fracionada de magmas TTG. Este autor advoga a existência no limite crosta inferior/manto superior de uma camada de rocha fundida, a qual seria a fonte de calor responsável pela geração deste grande volume de magmas graníticos no final do Arqueano. Davis et ai (1994) consideram, por sua vez, que a geração de magma granítico potássico no Arqueano seria resultado da colocação de magmas derivados do manto na base da crosta, associada com espessamento crustal, promovendo alta $\mathrm{T}$, metamorfísmo de baixa $\mathrm{P}$ e fusão crustal. Uma outra possibilidade, aventada por Sylvester (1994), é a de que as associações TTG, admitidas por ele como fontes dos magmas geradores dos grani tos arqueanos, poderiam ter-se formado não muito antes destes granitos potássicos arqueanos, e por isso, estariam relativamente aquecidas na época em que os granitos foram produzidos. Com isso, pequenos aumentos de temperatura poderiam induzir a fusão crustal, levando à formação de magmas graníticos. Além dos autores citados acima, Foden et al. (1984) e Cassidy et al. (1991) também admitem uma origem crustal para os magmas formadores dos granitos arqueanos.

Retornando aos granitos estudados, existe um amplo intervalo composicional e acentuados contrastes geoquímicos, tanto entre o Granodiorito Rio Maria e os leucogranitos estudados, quanto entre estes últimos e as associações TTG (Leite 1995). Não há, portanto, nenhuma evidência de que os líquidos formadores do Granito Xinguara possam resultar de diferenciação magmática através de cristalização fracionada a partir dos magmas formadores das demais associacões magmáticas arqueanas da região. Por outro lado, embora os dados disponíveis sobre o Granito Xinguara não permitam concluir que a sua origem se deu a partir da fusão parcial da crosta continental arqueana, os mesmos não se opõem à tal hipótese. Assume-se, com base nisto e nas hipóteses disponíveis na literatura, que os leucogranitos de Xinguara derivaram da fusão de granitóides arqueanos, representados por associações TTG ou afins ao Granodiorito Rio Maria.

Partindo-se da premissa de geração dos magmas graníticos através de processos de fusão parcial, duas hipóteses podem ser postuladas na tentativa de explicar a origem dos magmas dos LMG 1 e LMG2: (i) seriam produtos de diferentes graus de fusão parcial de uma mesma rocha fonte; (ii) poderiam ser derivados de rochas fontes de composições ligeiramente diferentes. Hipóteses análogas foram apresentadas e discutidas por Sylvester (1994) para explicar a origem dos leucogranitos cálcio-alcalinos arqueanos dos tipos 1 e 2, por ele distinguidos. Ele conclui que nenhuma dessas duas hipóteses poderia explicar razoavelmente as diferenças entre os mencionados granitos e assume, como alternativa, a interpretação que os contrastes entre os mesmos seriam devidos a diferenças nas profundidades de gerações dos respectivos líquidos. Essas se refletiriam na presença de maior proporção de minerais restitos nos granitos $\mathrm{CAI}$, em relação aos CA2, formados em maiores profundidades na crosta e capazes de uma separação mais efetiva de líquido e resíduo de fusão (Sylvester 1994).

Os leucogranitos LMG 1 e LMG2 de Xinguara mostram, entretanto, diferenças composicionais e mineralógicas bem menos expressivas que os dois tipos cálcio-alcalinos de Sylvester e são ambos geoquimicamente similares aos leucogranitos cálcio-alcalinos do tipo 2 (CA2), pois no diagrama $\mathrm{Rb} / \mathrm{Y}$ vs. $\mathrm{Al}_{2} \mathrm{O} 3 / \mathrm{TiO}_{2}$ (Fig. 4d) os leucogranitos estudados concentram-se sem exceção no domínio com altas razões $\mathrm{Rb} / \mathrm{Y}$ e $\mathrm{Al}_{2} \mathrm{O}_{3} / \mathrm{TiO}_{2}$, superpondo-se em parte ao campo dos granitos CA2, mas deles separando-se parcialmente por exibirem razões $\mathrm{Al}_{2} \mathrm{O}_{3} / \mathrm{TiO}_{2}$ mais elevadas. Logo, a hipótese de existência de diferenças nos níveis crustais de geração dos magmas, de modo análogo ao sugerido por Sylvester, não poderia ser aplicada para justificar os contrastes geoquímicos entre os leucogranitos estudados.

Retornando às hipóteses iniciais, diferentes graus de fusão parcial a partir de uma mesma fonte deveriam se refletir em comportamentos diferenciados de determinados elementos traço, tais como Rb, Y e Th, de um lado, e $\mathrm{P}, \mathrm{Sr}$ e $\mathrm{Cu}$, de outro, em função de seus diferentes coeficientes de partição entre líquido e resíduo (Sylvester 1994). Tais comportamentos são sugeridos pelos dados geoquímicos do plúton Xinguara (Tab. 1), cujos leucogranitos LMG2 são, em geral, comparativamente enriquecidos em $\mathrm{Y}$ e $\mathrm{Rb}$ (Fig. 2 e 3 ), além de $\mathrm{Th}$, e empobrecidos em Sr (Fig. 3), em relação aos LMG1. O P não mostra variações significativas entre os dois grupos e o $\mathrm{Cu}$ não foi analisado. Um teste de modelamento geoquímico efetuado para os elementos maiores através do programa MAGFRAC (Morris 1984), envolvendo a fusão parcial de biotita tonalitos e biotita-hornblenda-quartzo dioritos, encaixantes do plúton Xinguara e, muito provavelmente, similares geoquimicamente às suas rochas fonte, indicou efetivamente percentagens de fusão mais elevadas para a geração de líquidos com composição dos leucogranitos LMG 1 (em torno de $20 \%$ a partir dos tonalitos e de $15 \%$ aos quartzo-dioritos) do que para aqueles do tipo 2 (LMG2) (cerca de 10\% para ambos os tipos de rochas). Embora esse teste não forneça uma comprovação definitiva de que as rochas estudadas foram efetivamente geradas por tais processos, ele indica que existe a possibilidade de geração das mesmas a partir de líquidos derivados por diferentes graus de fusão parcial de uma mesma rocha fonte, não havendo, portanto, a necessidade de fontes distintas para explicar os contrastes entre os leucomonzogranitos LMG 1 e LMG2 do plúton Xinguara. Em função disso e das considerações anteriores, a hipótese de derivação dos dois líquidos a partir de uma mesma fonte é assumida neste trabalho. Os dados disponíveis sugerem que, tanto as rochas das associações trondhjemíticas, quanto as das séries cálcio-alcalinas ricas em $\mathrm{Mg}$, poderiam funcionar como fontes dos magmas. São, no entanto, necessários dados isotópicos, ora sendo obtidos, para aprofundar essa discussão.

As fácies granitos pegmatóides e sienogranitos são, conforme atestam as relações de campo, tardias e de menor volume (Leite 1995). Seria tentador admitir que estas fácies derivaram dos líquidos residuais dos dois tipos de leucomonzogranitos, porém os altos conteúdos de $\mathrm{Ba}$ e $\mathrm{Sr}$ dos sienogranitos e os conteúdos comparativamente baixos de $\mathrm{Rb}$ dos mesmos e dos granitos pegmatóides não favorecem a hipótese de que eles possam ter tal origem. Logo, é possível igualmente que os líquidos formadores dos mesmos também se relacionem a processos de fusão parcial.

Significado do Magmatismo Granítico Arqueano no Terreno GranltO-Greenstone de Rio Maria O magmatismo monzogranítico rico em $\mathrm{K}_{2} \mathrm{O}$, geralmente formado no final do arqueano, manifesta-se como corpos intrusivos nos terrenos gnáissicos e nas suites tonalítica-trondhjemítica-granodioríticas (TTG), sendo amplamente distribuído em vários locais do globo terrestre (Condie \& Hunter 1976, Cassidy et al. 1991, Krõner 1991, Sylvester 1994, Davis et al. 1994). Geralmente este evento magmático marca um importante estágio na evolução e estabilização da crosta arqueana (Ridley 1992). O plúton Xinguara é uma das intrusões mais representativas, dentre as diversas que caracterizam o magmatismo granítico rico em potássio de natureza cálcio-alcalina fortemente fracionado de idade arqueana do Terreno Granito-Greenstone de Rio Maria. Apesar de estar situado num contexto geológico um pouco distinto daquele do Granito Xinguara, o Granito Mata Surrão (Duarte 1992, Althoff 1996) mostra, além de características geológicas e petrográfícas, assinatura geoquímica similar à do Granito Xinguara (Leite 1995, Dall'Agnol et al. 1997). O Granito Guarantã, localizado na região de Marajoara, mostra algumas similaridades com o Granito Xinguara, porém exibe um comportamento bem distinto dos elementos terras raras (Althoff 1996).

Por outro lado, os dados estruturais e geocronológicos disponíveis (Souza 1994, Pimentel \& Machado 1994, Macambira \& Lafon 1995, Althoff 1996, Dall'Agnol et al. 1997) mostram que os diferentes leucogranitos arqueanos, embora correspondam ao evento final do magmatismo Arqueano no Terreno Granito-Greenstone de Rio Maria, formaram-se, em geral, logo após os granitóides TTG mais jovens e o Granodiorito Rio Maria, datados de 2,87 Ga. Portanto, o intervalo de tempo decorrido para a formação destes leucogranitos foi muito curto e eles não se situam no final do Arqueano, sendo inclusive bem mais antigos do que os leucogranitos da Suíte Plaque (Araújo \& Maia 1991, Avelar 1996), do Complexo Granítico Estrela (Barros 1997) e outros granitos alcalinos arqueanos (Lindenmayeref a/. 1994), descritos mais a norte.

Embora não se possa definir o volume do magmatismo granítico arqueano de Rio Maria em relação aos das demais associações, estimase que o mesmo represente uma porção muito significativa daqueles terrenos, tal como observado nos demais crátons arqueanos. 
CONCLUSÕES O Granito Xinguara é um dos mais expressivos corpos graníticos de idade arqueana do Terreno Granito-Greenstone de Rio Maria (TGGRM). Ele integra o magmatismo leucogranítico potássico que, a exemplo de outros crátons arqueanos, teve importância fundamental na evolução geológica do TGGRM. Esse magmatismo formou-se pouco após os demais tipos de granitóides arqueanos e, embora constitua o último evento magmático expressivo do TGGRM, não data do final do Arqueano, contrariamente ao verificado em certos crátons (Davis et al. 1994).

O Granito Xinguara é intrusivo em granitóides e gnaisses TTG e no Granodiorito Rio Maria. Petrograficamente é dividido em três fácies: leucomonzogranitos, granitos pegmatóides e leuco-sienogranitos. Com base em dados geoquímicos, a fácies leucomonzogranito foi subdividida em leucomonzogranitos do tipo 1 e tipo 2 (LMG1 e LMG2). Os conteúdos de $\mathrm{SiO}_{2}$ dos dois tipos de leucomonzogranitos se superpõem, entretanto os LMG2, quando comparados aos LMG1 são empobrecidos em $\mathrm{Al}_{2} \mathrm{O}_{3}, \mathrm{MgO}, \mathrm{CaO}$ e $\mathrm{Na}_{2} \mathrm{O}$ e enriquecidos em $\mathrm{KiO}, \mathrm{Rb}, \mathrm{Zr}$ e $\mathrm{Y}$. Os leuco-sienogranitos e granitos pegmatóides tendem a ser mais ricos em $\mathrm{SiO} 2$ do que os leucomonzogranitos e empobrecidos em $\mathrm{MgO}, \mathrm{FeO}_{\mathrm{t}}$ e $\mathrm{CaO}$.

O plúton Xinguara exibe uma marcante homogeneidade composicional, sendo formado por leucogranitos metaluminosos a ligeiramente peraluminosos com altos teores de $\mathrm{SiO}_{2}$ e álcalis, elevadas razões $\mathrm{K}_{2} \mathrm{O} / \mathrm{Na}_{2} \mathrm{O}$, e baixos teores médios de $\mathrm{MgO}$ e moderados de $\mathrm{CaO}$. Os LMG1 e LMG2 definem nos diagramas geoquímicos dois trends evolutivos, indicando que cristalizaram a partir de líquidos distintos. O comportamento dos elementos litófilos sugere que processos de cristalizacãa fracionada moderada aluaram durante a formação dos magmas do plúton Xinguara, havendo fracionamento de feldspato potássico, plagioclásio e biotita, sendo o fracionamento de feldspatos indicado também pelas expressivas anomalias negativas de $\mathrm{Eu}\left(\mathrm{Eu} / \mathrm{Eu}^{*}\right.$ variando de 0,28 a 0,38 nos LMG1). Os LMG1 mostram, em geral, acentuado empobrecimento nos elementos terras raras pesados $\left(\mathrm{La}_{\mathrm{n}} / \mathrm{Yb}_{\mathrm{n}}\right.$ variando de 149,07 a 16,63) causado, provavelmente, pela retenção de granada e/ou anfibólios no resíduo de fusão.
Os dados geoquímicos apontam para uma similaridade do Granito Xinguara com os leucogranitos cálcio-alcalinos arqueanos do tipo 2 (CA2) definidos por Sylvester (1994). Há semelhanças, sobretudo, no acentuado fracionamento de elementos terras raras pesados, na presença de expressiva anomalia negativa de $\mathrm{Eu}$ e de empobrecimento em $\mathrm{Y}$, Ti e Nb, paralelamente a enriquecimento em $\mathrm{P}$ e Sr (Figs. 4a e c). Os altos valores das razões $\mathrm{Rb} / \mathrm{Y}$ e $\mathrm{Al}_{2} \mathrm{O}_{3} / \mathrm{TiO}_{2}$ dos leucogranitos Xinguara (Fig. 4c) também reforçam esta interpretação.

A hipótese de contaminação do magma original pelas rochas encaixantes parece pouco sustentável, sendo mais provável que os dois tipos de leucogranitos do plúton Xinguara tenham se originado a partir de líquidos distintos, os quais evoluíram independentemente. $\mathrm{O}$ amplo intervalo composicional e os fortes contrastes geoquímicos entre o Granito Xinguara e suas rochas encaixantes (Granodiorito Rio Maria e as associações TTG) não fortalecem tampouco a hipótese de que os líquidos formadores do plúton Xinguara possam resultar de diferenciação magmática dos magmas formadores das mesmas. Assume-se, portanto, que os leucogranitos Xinguara derivaram da fusão de granitóides arqueanos, representados por associações TTG ou afins ao Granodiorito Rio Maria, sendo mais provavelmente produtos de diferentes graus de fusão parcial de uma mesma rocha fonte, conforme sugerido por testes de modelamento geoquímico, bem como pelo comportamento de $\mathrm{Rb}, \mathrm{Y}$, Th e $\mathrm{Sr}$.

Agradecimentos Aos pesquisadores do Grupo de Pesquisa Petrologia de Granitóides (GPPG-CG-UFPa) pelo apoio nas diversas etapas deste trabalho, em especial a C.E.M. Barros, R.O. Silva Jr., C.M. Soares, H.T. Costi e M.A.B.M. Figueiredo. Ao químico R.N. Oliveira da Companhia ALBRÁS pela realização das análises químicas de elementos maiores. Ao Prof. W.K. Schuckman (in memoriam) pela realização da maioria das análises de elementos traço. Este trabalho recebeu o apoio financeiro de PADCT-FINEP (Processo 6.5.92.0025.00), CNPq, CAPES e Curso de Pós-Graduação em Geologia e Geoquímica (CPGG-CG-UFPA). A dois revisores anónimos da RBG pelas sugestões e críticas.

\section{Referências}

Althoff F.J. 1996. Estude pétrologique et síructurale dês granitóides de Marajoara (Pará, Brésil): leur role dans l 'évolution archéenne du craton Amazonien (2,7-3,2 Ga). Université Henri Poincaré, Nancy I-France, Tese de Doutoramento, 296p.

Althoff F.J., Barbey P., Macambira M.J.B., Scheller T., Leterrier J., Dall'Agnol R., Lafon J.M. 1998. La croissance du craton sud-amazonien (région de Rio Maria, Brésil). In: Réunion dês Sciences de Ia Terre. Resumes. Brest, Soe. Géol. Fr. p. 62.

Anders E. \& Grevesse N. 1989. Abundances of the elements: Meteoritic and solar. Geochimica et Cosmchimica Acta, 53: 197-214.

Araújo O.J.B., Macambira E.M.B., Vale A.G., Oliveira J.R., Silva Neto C.S., Costa E.J.S., Santos A., Pena Filho J.I.C., Neves A.P., Jorge João X.S., Costa J.B.S. 1994. Primeira integração das investigações geológicas do Programa Grande Carajás na região SSE do Estado do
Pará. In: SBG, Simpósio de Geologia da Amazónia, 4, Belém, 1994. Boletim de Resumos Pará. In: SBG, Simposio p. $299-301$.

Araújo O.J.B. \& Maia R.G.N. 1991. Programa de levantamentos geológicos básicos do Brasil, Serra dos Carajás, folha SB-22-Z-A, Estado do Pará. Texto explicativo, Brasília, DNPM/CPRM. 164p.

Avelar V.G. 1996. Geocrologia Pb-Pb por evaporação em monocristal de zircão, do magmatismo da região de Tucumã, SE do Estado do Pará, Amazónia oriental. Universidade Federal do Pará, Tese de Mestrado, $199 \mathrm{pp}$.

Barros C.E.M. 1997. Pétrologie et structure du Complexe Granitique Estrela $(2.5 \mathrm{Ga})$ et de son encaissant métavolcano-sédimentaire (Province Métallifêre de Carajás, Brésil). Université Henri Poincaré - Nancy 1, France.Nancy, Tese de Doutorado, 316p..

Cassidy K.F., Barley M.E., Groves D.I., Perrng C.S., Hallberg J.A. 1991. An overview of the nature, distribution and inferred tectonic setting of granitoids in the Late Archean Norseman-Wiluna Belt. Precambrian Research., 51:51-83.

Chappell B.W. \& White J.R. 1992.1-and S-type granites in the Lachlan Fold Belt. Transactions Royal Society. Edinburgh: Earth Science., 83: 1-26.

Condie K.C. 1993. Chemical composition and évolution of the upper continental crust: Contrasting results from surface samples and shales. Chemical Geology, 104: 1-37.

Condie K.C. \& Hunter D.R. 1976. Trace elements geochemistry of Archean granitic rocks from Barberton région, South África. Earth and Planetary Science Lefiers, 29:389-400.

Dall'Agnol R., Ramo O.T., Magalhães M.S., Macambira M.J.B. 1999. Petrology of the Anorogenic, Oxidised Jamon and Musa Granites, Amazonian Craton: implications for the Génesis of Proterozoic A-Type Granites. Lithos, 46:431-462.

Dall'Agnol R., Souza Z.S., Althoff F.J., Barros C.E.M., Leite A.A.S., Jorge João X.S. 1997. General aspects of the granitogenesis of the Carajás metallogenic province. In: International Symposium on Granite and Associated Mineralizations, 2. Extended abstracts andprogram, Salvador, 1997, pp. 135-161.

Davis W.J., Fryer B.J., King J.E. 1994. Geochemistry and évolution of late Archean plutonism and its significance to the tectonic development of the Slave Craton. Precambrian Research. 67:207-241.

Duarte K.D. 1992. Geologia e geoquímica do Granito Mata Surrão (SWde Rio Maria-Pa): um exemplo de granito "stricto sensu" Arqueano. Universidade Federal do Pará, Tese de Mestrado, 217p.

Foden J.D., Nesbitt R.W., Rutland R.W.R. 1984. The geochemistry and crustal origin of the Archean acid intrusive rocks of the Agnew Dome, Lawlers, Westwen Austrália. Precambrian Research, 23: 247-271.
Hanson G.N. 1989. An approach to trace element modeling using a simple igneous system as an example. In: Ribbe P.H. (Ed.) Geochemistry and mineralogy of rare earth alements. Reviews in Mineralogy, 21: 79-97.

Huhn S.R.B., Santos A.B.S., Amaral A.F., Ledsham E.J., Gouveia J.L., Martins L.B.P., Montalvão R.M.G., Costa V.G. 1988. O terreno grznilo-greenstone da região de Rio Maria-sul do Pará. In: SBG, Congresso Brasileiro de Geologia, 35, Belém, Anais. 3. 1438-1453.

Krõner A. 1991. Tectonic evolution in the Archean and Proterozoic. Tectonophisics, 87:393-410.

Leite A.A.S. 1995. Geologia e geoquímica do maciço granítico arqueano Xinguara - sudeste do Estado do Pará. Universidade Federal do Pará, Tese de Mestrado, 209p.

Leite A.A.S. \& Dall'Agnol R. 1997. Geologia e petrografia do maciço granítico Arqueano Xinguara e de suas encaixantes -SE do Pará. Boletin do Museu Paraense Emílio Goeldi Série Ciência da Terra 9: 43-81.

Lindenmayer Z.G., Fyfe W.S., Bocalon V.L.S. 1994. Nota preliminar sobre as intrusões granitóides do depósito de cobre do Salobe, Carajás. Acta Geológica Leopoldensia, 17(40): 153-184.

Macambira M.J.B.\& Lafon J.M. 1995. Geocronologia da Província Mineral de Carajá; síntese dos dados e novos desafios. Boletim do Museu Paraense Emilio Goeldi, série Ciências da Terra, 1: 263-288.

Martin H. 1994. The Archean grey gneisses and the gneisses of continental crust. In: Condie K. C. (ed.) Developments in precambrian geology $U$. Archean crustal évolution, Elsevier, p. 205-259.

Medeiros H. \& Dall'Agnol R. 1988. Petrologia da porção leste do Batólito Granodiorítico Rio Maria, sudeste do Pará. In: SBG, Congresso Brasileiro de Geologia, 35, Belém. Anais. 3:1488-1499.

Morris P.A. 1984. MAGFRAC: a basic program for least -squares aproximation of fractional crystallization. Computer \& Geosciences, 10: 437-444.

Pearce J.Ã., Harris N.B.W., Tindle A.G. 1984. Trace element discrimination diagrams for the tectonic interpretation of granitic rocks. Journal of Petrology, 25: 956-983.

Pimentel M.M. \& Machado N. 1994. Geocronologia U-Pb dos terrenos granito-greenstone de Rio Maria, Pará. In: SBG, Congresso Brasileiro de Geologia, 38, Camboriú. Boletim de Resumos Expandidos, p. 390-391.

Ridley J.R. 1992. The thermal causes and effects of voluminous, late Archaen: terrains, processes and metallogeny. Geology Dept. \& University Extension, The University of Western Austrália Publications, 22:275-285.

Souza Z.S. 1994. Geologia e petrogênese do "Greenstone Belt" Identidade: implicações sobre a evolução geodinâmica do terreno granito-"greenstone" de Rio Maria, SE do Pará. Universidade Federal do Pará, Tese de Doutorado.Vol. 1 e 2, 624p.

Sylvester R.P.J. 1994. Archean granite plutons. In: Condie K. C. (ed.) Developments in precambrian geology 11. Archean crustal évolution, Elsevier, p. 261-314

Sylvester P J. 1989. Post-collisional alkaline granites. Journal of Geology, 97:261-280.

Taylor S.R. \& McLennan S.M. 1985. The continental crust: Its composition and evolution. Backwell Scientific, Oxford, $321 \mathrm{p}$ 